REVISTA DE GESTÃO E SECRETARIADO

MANAGEMENT AND ADMINISTRATIVE

PROFESSIONAL REVIEW

ISSN: 2178-9010
Revista GeSec

São Paulo, SP, Brasil

v. 12 , n. 1, p. 133-159

jan. /abr. 2021

DOI: http://dx.doi.org/10.7769/gesec.v12i1.1130

\title{
Empreendedorismo sustentável: mapeamento da produção científica internacional entre 2009 e 2019
}

\section{Sustainable entrepreneurship: mapping of international scientific production between 2009 and 2019}

\author{
Paloma Bezerra ${ }^{1}$ \\ Sandra Araújo de Souza ${ }^{2}$ \\ Geuda Gonçalves ${ }^{3}$
}

\section{Resumo}

Esta pesquisa teve o objetivo de mapear a produção científica internacional sobre empreendedorismo sustentável entre os anos de 2009 e 2019. Realizou-se um estudo exploratório e descritivo, no qual os dados foram coletados na base de dados da Web Of Science. Foram delineados a evolução da produção científica sobre o tema, os autores mais prolíficos e as fontes de publicação com maior volume de publicações. O software bibliométrico VOSViewer foi utilizado para analisar as redes bibliométricas de: coocorrência de palavras-chave, coautoria e cocitação. Concluiu-se que o tema apresentou evolução no cenário internacional. E que houve dispersão nos estudos sobre o tema em relação às fontes de publicação. Os estudos integraram o empreendedorismo tradicional com diferentes eixos de pesquisa, em especial quanto à inovação, à gestão estratégica, ao empreendedorismo institucional e à sustentabilidade social e ambiental.

Palavras-chave: Empreendedorismo sustentável. Produção científica internacional. Redes bibliométricas.

\section{Abstract}

This research aimed to map the international scientific production on sustainable entrepreneurship between the years 2009 and 2019. An exploratory and descriptive study was

\footnotetext{
${ }^{1}$ Mestranda no Programa de Pós-graduação em Administração da Universidade Federal de Campina Grande (UFCG).

${ }^{2}$ Doutora em Recursos Naturais, Docente na Universidade Estadual da Paraíba (UEPB).

${ }^{3}$ Doutora em Recursos Naturais, Docente na UEPB.
} 
carried out, in which data was collected in the Web Of Science database. The evolution of scientific production on the subject, the most prolific authors and the sources of publication with the greatest volume of publications were outlined. The bibliometric software VOSViewer was used to analyze the bibliometric networks of: co-occurrence of keywords, co-authorship and citation. It was concluded that the subject presented evolution in the international scenario. And that there was dispersion in studies on the subject in relation to sources of publication. The studies integrated traditional entrepreneurship with different research axes, especially regarding innovation, strategic management, institutional entrepreneurship and social and environmental sustainability.

Keywords: Sustainable entrepreneurship. International scientific production. Bibliometric networks.

\section{Introdução}

O empreendedorismo, sempre visto como um agente de transformação social, em especial para a dimensão econômica, passou a ser considerado também como o veículo que pode colaborar para o desenvolvimento sustentável (Borges, Borges, Ferreira, Najberg, \& Tete, 2014). Nesse sentido, o empreendedorismo sustentável destaca-se como forma de agregar ações que gerem resultados sociais e ambientais à atividade econômica. $\mathrm{O}$ empreendedorismo sustentável é um processo de missão orientado a resolver problemas ambientais e sociais de insustentabilidade por meio da exploração de oportunidades de mercado criadas com modelos de negócios inovadores (Schaltegger, Luedeke-Freund, \& Hansen, 2016).

O empreendedorismo sustentável reúne diferentes interpretações. Pode ser compreendido como um guarda-chuva conceitual para o empreendedorismo ambiental, o empreendedorismo verde, o empreendedorismo social, etc. (Majid \& Koe, 2012). Estudos que contribuíram para a ampliação deste campo temático confirmaram essa heterogeneidade da área, evidenciando a aplicabilidade do conceito em vários contextos, tais como o empreendedorismo social, o empreendedorismo institucional, o empreendedorismo ecológico etc. Esses aspectos podem ser consultados nas seguintes pesquisas: Hall, Daneke e Lenox (2010), Shepherd e Patzelt (2011), Gast, Gundolf e Cesinger (2017), Bansal, Garg e Sharma (2019), Thananusak (2019), dentre outros.

Como é possível observar, essas produções se concentraram em subcategorias do empreendedorismo sustentável enfocando, preponderantemente, a realização de síntese 
crítica, síntese narrativa, ou meta-análise (Thananusak, 2019). Deste modo, manifesta-se como oportuna a realização de análises de redes bibliométricas, que utiliza medidas de relações entre unidades bibliométricas (a exemplo de periódicos, de autores, de palavraschave, etc.) e geram representações gráficas que propiciam a classificação e a estruturação do campo de pesquisa diante dos conjuntos de dados encontrados na literatura (Knutas, Hajikhani, Salminen, Ikonen, \& Porras, 2015).

À vista disso, esta pesquisa tem como objetivo mapear a produção científica internacional sobre empreendedorismo sustentável entre os anos de 2009 e 2019. Quanto aos objetivos específicos, busca-se: a) apresentar a distribuição temporal das publicações, b) mapear os periódicos com maior volume de publicações, c) identificar os autores mais prolíficos e d) analisar redes de coocorrência de palavras-chave, redes de cocitação e redes de coautoria.

O presente artigo está estruturado em cinco seções, sendo esta introdução a primeira. $\mathrm{Na}$ segunda são expostos os principais tópicos a respeito do empreendedorismo sustentável, bem como são apresentados os indicadores bibliométricos utilizados para o desenvolvimento deste estudo. Na terceira seção, são apresentados os procedimentos metodológicos utilizados na pesquisa. Na quarta seção são expostas as análises e discussões dos resultados. Por fim, a última seção apresenta as considerações finais que incluem contribuições, limitações e sugestões para pesquisas futuras.

\section{Referencial teórico}

\subsection{Empreendedorismo sustentável}

Os primeiros estudos sobre empreendedorismo se concentraram nas visões tradicionais sobre os negócios, orientados preponderantemente para o lucro (Schaltegger \& Wagner, 2011). Devido à crescente conscientização a respeito do desenvolvimento sustentável, observam-se empreendedores motivados com ações que visam à mitigação de impactos sociais e de impactos ambientais (Parrish, 2010).

O desenvolvimento sustentável requer a conquista integrativa entre objetivos econômicos, sociais e ambientais para a sociedade atual e para as gerações futuras. Nesse sentido, como distinção para muitas perspectivas do empreendedorismo convencional, o empreendedorismo sustentável inclui outras dimensões além do sucesso do mercado (Schaltegger \& Wagner, 2011). 
O empreendedorismo sustentável visa à obtenção de lucro, à criação de valores sociais e ambientais por meio da produção de bens e de serviços que contribuem com o desenvolvimento sustentável. Nesse sentido, os empreendedores que procuram identificar e explorar oportunidades advindas do ambiente natural e do ambiente social estão relacionados ao empreendedorismo sustentável (Shepherd \& Patzelt, 2011).

Esse tipo de empreendedorismo é mais amplo e complexo em comparação com os outros, é um campo de pesquisa recente que possui várias interpretações e exige um olhar holístico (Tilley \& Young, 2009; Boszczowski \& Teixeira, 2012). Pode ser considerado um termo genérico para empreendedorismo ambiental, Ecopreneurship e empreendedorismo social; no entanto, cabe destacar que esses termos são sobrepostos, sendo difícil desenhar um limite nítido entre eles (Gibbs, 2009). Os principais tipos de empreendedorismo podem ser observados no Quadro 1.

\section{Eixo temático \\ Descrição}

Econômico Orientado pela descoberta e pela exploração de oportunidades para obter lucro, através de processos de abertura de empreendimentos, assunção de risco, inovação de produtos ou de processos.

Ambiental Ambiental ou ecologicamente correto, conservando os recursos naturais e criando desenvolvimento econômico.

Ecopreneurship Distingue-se de outras formas de desenvolvimento ambiental corporativo pelo vívido compromisso da empresa com o progresso ambiental, combina as atividades com a sensibilização ambiental.

Social Ser incorporado socialmente através da complementação social e das metas.

Sustentável Orientado para o futuro, equilibrando os esforços para viabilizar a prosperidade econômica, a justiça social e a conservação ambiental.

Quadro 1. Tipos de empreendedorismo

Fonte: Gibbs (2009), Tilley e Young (2009) e Richomme-Huet e Freyman (2011)

Com base no exposto, é possível observar que o empreendedorismo está passando por um processo de mudança, as práticas empreendedoras passaram a incluir campos que não foram relacionados a eles anteriormente (Tilley \& Young, 2009). Essas mudanças mercadológicas proporcionaram oportunidades de negócio para que o empreendedorismo se destacasse como fenômeno catalisador do desenvolvimento sustentável (Cicconi, 2013). Os empreendedores sustentáveis podem atuar como condutores da transição para uma economia 
sustentável e preencher as falhas deixadas por empresas e por órgãos governamentais (Parrish \& Foxon, 2009). A próxima seção reúne os indicadores bibliométricos que serão utilizados como suporte científico no decorrer do escrito.

\subsection{Análises bibliométricas}

A pesquisa bibliométrica mensura a produção e a difusão do conhecimento científico através da análise quantitativa da informação bibliográfica, é capaz de mensurar, por exemplo, a influência de pesquisadores e de periódicos em determinada área, possibilitando fazer um recorte do perfil e suas inclinações, desse modo, evidenciando os eixos temáticos (Oliveira, Barbosa, Rezende, Silva, \& Albuquerque, 2013).

Segundo Egghe (2005), os estudos bibliométricos, tradicionalmente, são conduzidos por três leis básicas, a saber:

- Lei de Bradford: avalia a dispersão da produção científica sobre determinada área entre as fontes de publicação. Isto é, segmenta toda a produção científica em grupos com a mesma quantidade de publicações, onde os primeiros grupos apresentam um número menor de periódicos (os de maior produtividade), enquanto nos grupos seguintes é constatada uma quantidade maior de revistas publicando o mesmo número de artigos;

- Lei de Zipf: analisa a frequência de palavras em um texto, de modo que um pequeno grupo de palavras tem maior número de ocorrência, enquanto muitos palavras têm frequência menor, desta forma, os termos com maior incidência determinarão o tema central de um documento;

- Lei de Lotka: estima a produtividade de autores através de um modelo de distribuição tamanho-frequência em um conjunto de estudos. Prevê que, em determinado período, a relação entre a quantidade de autores e o volume de artigos de sua autoria decresceria, ou seja, poucos dos pesquisadores publicam muito, enquanto a maioria publica pouco.

Outros indicadores bibliométricos vêm sendo desenvolvidos na literatura sobre a mensuração da produção científica. Nesse sentido, este estudo, além de identificar os periódicos e os autores mais prolíficos, também mapeia as redes de coocorrência de palavraschave, de coautoria e de cocitação.

A análise de coautoria evidencia a colaboração entre dois ou mais autores, gerando redes de coautorias que revelam as características da comunidade acadêmica e a estrutura do 
conhecimento, contribuindo para um aumento na produção científica (Silva, Durante, \& Biscoli, 2017). A coocorrência de palavras-chave se refere à utilização de padrões de termoschave como mecanismo para compreender a estrutura de ideias dispostas nas produções científicas (Whittaker, 1989). Já a cocitação consiste em identificar a frequência com que dois documentos da literatura prévia são citados juntos pela literatura posterior, sendo uma relação estabelecida por autores citantes e que varia segundo os interesses e os padrões intelectuais do campo em estudo (Small, 1973). A próxima seção evidencia os procedimentos metodológicos utilizados para a realização deste estudo.

\section{Metodologia}

Para mapear a produção científica internacional sobre empreendedorismo sustentável entre os anos de 2009 e 2019, realizou-se uma pesquisa exploratória e descritiva, com abordagem quantitativa, bem como do tipo bibliométrica, pois além de mensurar aspectos da produção científica, analisa redes de coocorrência de palavras-chave, de cocitação e de coautoria. Os dados para realização desta pesquisa foram extraídos da base de dados da Web Of Science, a partir dos critérios explicitados no Quadro 2.

\begin{tabular}{|c|c|}
\hline Elementos & Parâmetros \\
\hline Palavras-chave & $\begin{array}{l}\text { Entrepreneurship. Green Entrepreneurship, Sustainable entrepreneurship, } \\
\text { Ecopreneurship, Environmental entrepreneurship, Social entrepreneurship, Triple } \\
\text { Bottom Line, TBL, Social dimension, Economic dimension, Environmental } \\
\text { dimension, Sustainability, Sustainable development, Corporate social } \\
\text { responsibility, Corporate social-responsibility, Sustainable society. }\end{array}$ \\
\hline Índices de citações & $\begin{array}{ll} & \text { Science Citation Index Expanded - SCIE, } \\
-\quad & \text { Social Science Citation Index (SSCI), } \\
\text { - } \quad \text { Arts and Humanities Citation Index (A\&HCI) } \\
\text { - Emerging Sources Citation Index (ESCI) }\end{array}$ \\
\hline Tempo estipulado & $2009-2019$ \\
\hline Tipo de Documento(s) & Todos \\
\hline Idioma(s) & Inglês e Português \\
\hline
\end{tabular}

Quadro 2. Elementos e critérios de busca utilizados na Web of Science

Fonte: Dados da pesquisa (2020)

A busca inicial realizada a partir da Web Of Science resultou em 1.454 documentos. Seguidamente, os documentos do tipo Early Access foram removidos, pois são produções de 
acesso antecipado, isto é, disponibilizados para a biblioteca antes de serem atribuídos à edição final. Assim, o conjunto final de artigos analisados reúne 1.430 produções.

Dois tipos de análises foram realizados: o primeiro esforço enquadra uma análise descritiva com o auxílio do software Microsoft Excel para construir os gráficos de distribuição dos artigos por ano de publicação, por periódico científico e por autores. O segundo momento foi direcionado à construção das redes bibliométricas, utilizando-se a ferramenta VOSViewer para mapear as redes de coocorrência de palavras-chave, de cocitação e de coautoria.

\section{Análise e discussão dos resultados}

\subsection{Evolução temporal das publicações}

A distribuição das publicações no período pesquisado (2009-2019) é mostrada no Gráfico 1. Nesse período, a produção científica sobre o empreendedorismo direcionado à sustentabilidade, indexada na base Web Of Science, iniciou com os artigos de: Vaz e Nijkamp (2009), intitulado "Knowledge and innovation: The strings between global and local dimensions of sustainable growth", publicado no Entrepreneurship and Regional Development; Brown, de Jong, e Lessidrenska (2009), intitulado "The rise of the Global Reporting Initiative: a case of institutional entrepreneurship", publicado no Environment al Politics; e Oukil (2009), intitulado "Enhancing innovation for sustainable growth and competitiveness in North African countries", publicado no International Journal Of Technology Management.

Esses estudos abordaram a sustentabilidade como uma nova lógica institucional e tratam dois mecanismos relevantes nesse processo: empreendedorismo institucional e inovação. Brown et al. (2009) tratam sobre o empreendedorismo institucional, especificamente estudam a contribuição da Global Reporting Initiative na criação de um novo padrão de relatórios de sustentabilidade para empresas em todo o mundo, viabilizando o diálogo entre diversos atores da sociedade que possuem necessidades e interesses amplamente variados, pois em meados da década de 1990 as empresas estavam lançando um extenso volume de informações, geralmente inconsistentes e que dificultavam a interpretação e a comunicação com as partes interessadas.

Já Vaz e Nijkamp (2009) e Oukil (2009) destacam a inovação como um fator determinante de desempenhos positivos na operacionalização da sustentabilidade. A inovação leva às adaptações e ao aprendizado, o resultado é um gradual progresso que conduz a 
melhorias ou mudanças. O forte elo entre inovação e empreendedorismo sugere que a riqueza e o crescimento são criados a partir de novas ideias. Essas inovações podem resultar da necessidade de solucionar problemas ou do pensamento crítico de indivíduos (Oukil, 2009).

O crescimento econômico é caracterizado por uma competitividade global e por uma necessidade de promoção da sustentabilidade. Nesse sentido, o esforço de combinar, na cadeia produtiva, a inovação e a coordenação das organizações representa mais do que um desafio teórico, mas sim uma transformação social (Vaz \& Nijkamp, 2009).

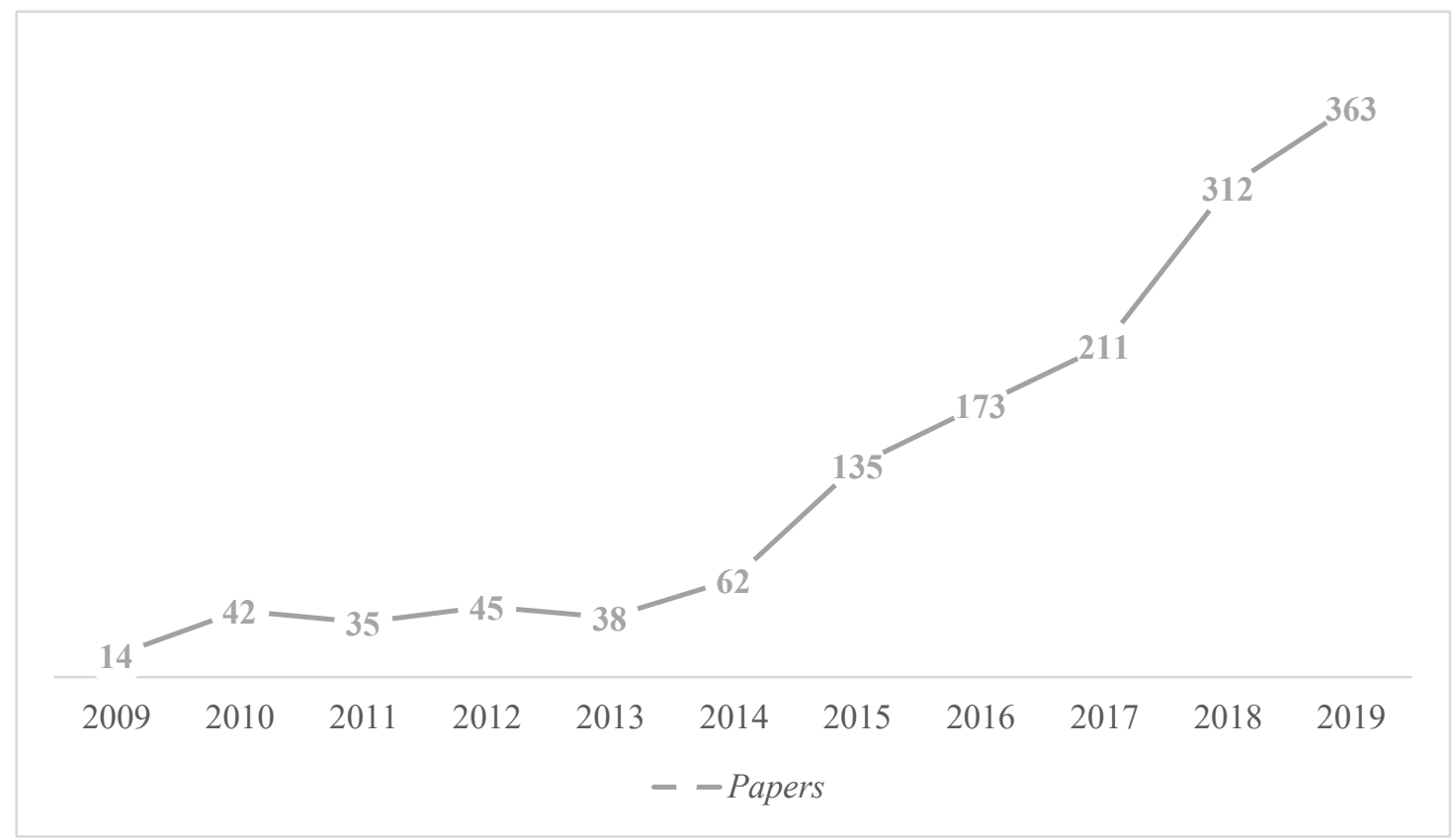

Gráfico 1. Distribuição dos artigos por ano de publicação

Fonte: Dados da pesquisa (2020)

Desde 2014 a quantidade de publicações sobre o tema está em ascensão. O alto número de publicações é encontrado para o período entre 2015 e 2019 . O ano de 2019 foi o que apresentou maior concentração da produção científica sobre o tema, com 363 documentos distribuídos em journals, com destaque para o Sustainability (66 publicações), seguido do Journal Of Cleaner Production (16 publicações) e do Journal Of Business Ethics (13 publicações).

Pode-se observar que, nos últimos anos, houve uma variedade de iniciativas de produtores, de consumidores e de outros atores sociais com o intuito de internalizar, de minimizar ou de neutralizar as externalidades ambientais (Tarnanidis, Papathanasiou, \& Subeniotis, 2019). Em 2015, as Nações Unidas divulgaram a Agenda 2030, definindo 17 metas de desenvolvimento sustentável. A sustentabilidade ganhou cada vez mais consciência pública ao longo dos últimos anos, a partir do reconhecimento dos impactos causados pelo 
aumento da população e do consumo de recursos naturais (Vallaster, Kraus, Kailer, \& Baldwin, 2019).

Deste modo, o aumento do volume de publicações pode estar associado aos seguintes fatores principais, a seguir:

- aumento de pressões sociais (acionistas, poder público, clientes etc.) pela divulgação e pela transparência dos desempenhos organizacionais em termos de sustentabilidade;

- maior articulação entre os atores sociais (poder público, empresas, sociedade civil etc.) visando ao estabelecimento e ao monitoramento de estratégias e de políticas para o desenvolvimento sustentável, a exemplo da Agenda 2030 e de outros acordos estabelecidos, especialmente, a partir da década de 90.

\subsection{Distribuição dos artigos por fontes de publicação}

Os 1.430 documentos estão distribuídos em 562 fontes de publicação. Este resultado confirma, portanto, a Lei de Bradford, ao apontar uma dispersão da produção científica por um volume amplo de periódicos. Tendo em vista a quantidade de publicações e a dispersão da produção científica sobre o empreendedorismo sustentável, optou-se por organizar as fontes de publicações em três grupos: o primeiro grupo é composto por periódicos com pelo menos 15 publicações, o que corresponde a 1,4\% (oito periódicos). O segundo grupo é constituído por periódicos que contemplam entre dois e 12 publicações, cerca de 33,3\% (187 periódicos). O terceiro grupo reúne periódicos com apenas uma publicação, o equivalente a 65,3\% (367 periódicos). Por sua vez, o Gráfico 2 apresenta a distribuição das fontes de publicação com maior volume de artigos na amostra ora investigada, isto é, o primeiro grupo. 


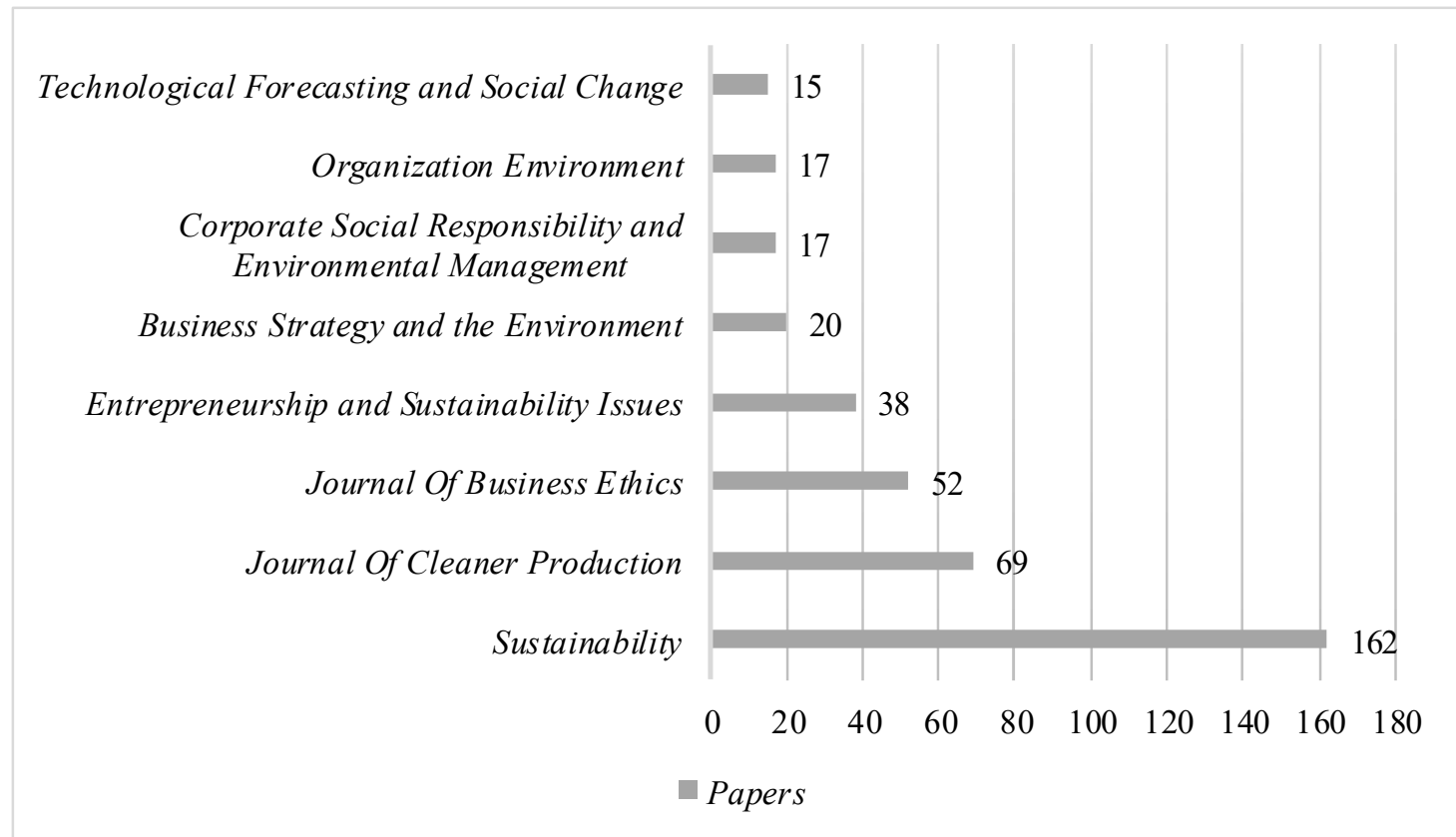

Gráfico 2. Distribuição dos artigos por periódicos

Fonte: Dados da pesquisa (2020)

Os periódicos que concentram o maior número de publicações são: Sustainability e Journal Of Cleaner Production, sendo 162 e 69 a quantidade de artigos publicados, respectivamente. A soma das publicações desses periódicos totaliza 231 artigos, que estão organizados na plataforma da Web Of Science em três principais campos de pesquisa, a saber: Environmental Sciences Ecology (231 artigos, 100\%), Science Technology Other Topics (231 artigos, 100\%) e Engineering (69 artigos, $29.8 \%$ ).

O Journal of Cleaner Production é um periódico internacional transdisciplinar com foco nas práticas de Sustentabilidade e de Produção Mais Limpa, que é uma ferramenta ambiental utilizada para minimizar a produção de resíduos, enquanto aumenta a eficiência nos usos de energia, de água e de outros recursos (Journal of Cleaner Production, 2020). A Sustainability é uma revista interdisciplinar sobre sustentabilidade e desenvolvimento sustentável, com ênfase para as dimensões: ambiental, cultural, econômica e social (Sustainability, 2020). Deste modo, observa-se que os artigos estão concentrados em periódicos que tratam sobre sustentabilidade a partir de um escopo interdisciplinar, abrangendo práticas de sustentabilidade que podem ser úteis para empresas, governos e outras organizações em diferentes contextos, uma vez que o conceito de sustentabilidade associado ao desenvolvimento sustentável é embrionário e está fundamentado principalmente em duas áreas: na economia e na ecologia, conforme pode ser consultado em Veiga (2010). 


\subsection{Autores com maior volume de publicações}

Dos 3.369 autores que compõem a amostra, cerca de 90,5\% (3.049 autores) publicaram apenas um artigo, enquanto 7,4\% (249 autores) publicaram pelo menos 2 artigos. 1,2\% (40 autores) publicaram pelo menos 3 artigos. Publicaram pelo menos 4 artigos 0,5\% (18 autores). Somente $0,4 \%$ dos autores investigados (13 autores) publicaram cinco ou mais artigos. O Gráfico 3 apresenta os autores mais importantes, considerando o volume de publicações.

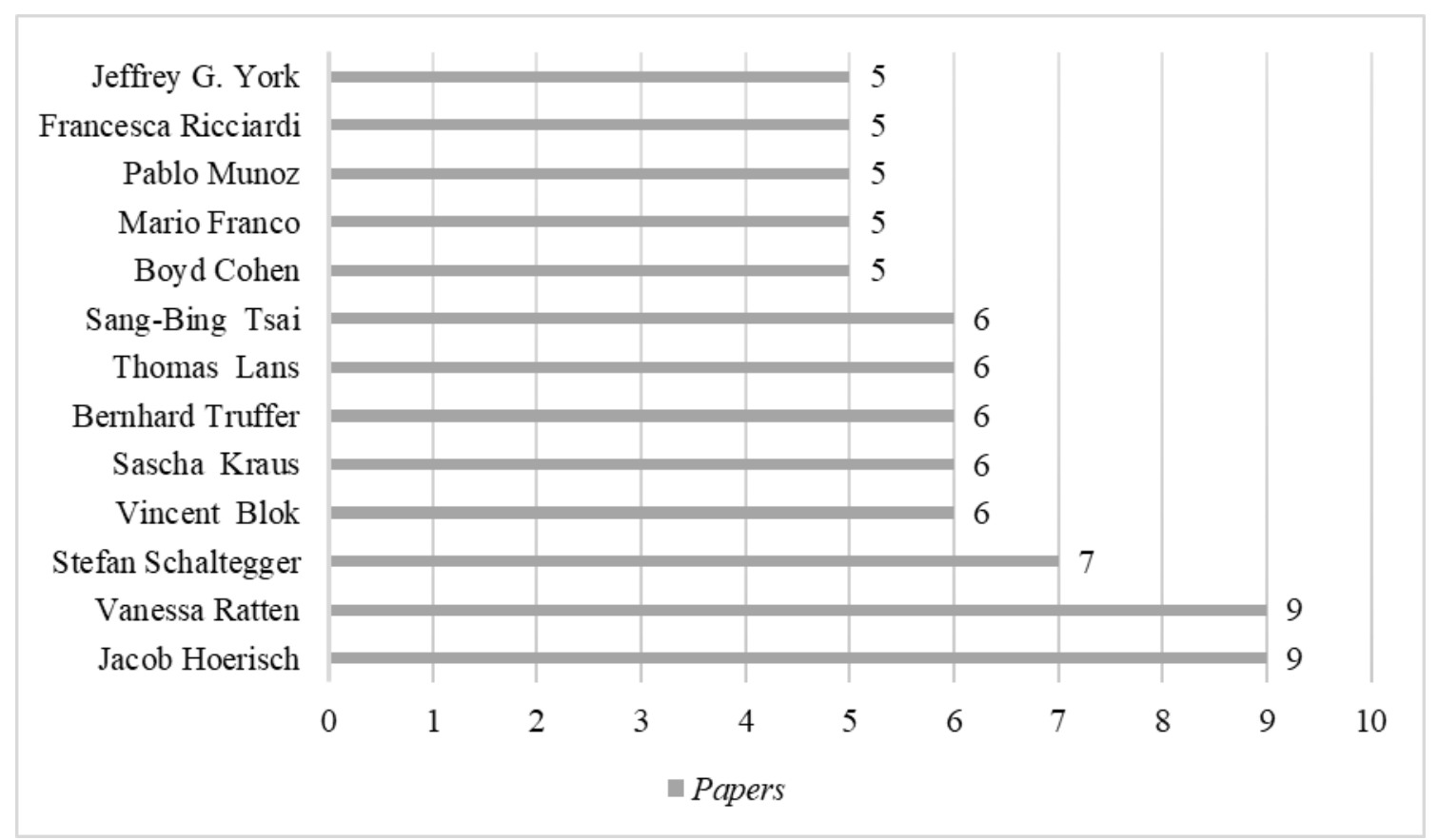

Gráfico 3. Autores com maior volume de publicações

Fonte: Dados da pesquisa (2020)

Os autores com a quantidade de publicações mais expressiva são Vanessa Ratten e Jacob Hoerisch, com nove artigos publicados.

Vanessa Ratten destaca-se ao conectar as literaturas de empreendedorismo, gestão esportiva e responsabilidade social. Desenvolveu uma teoria do empreendedorismo esportivo que incorpora diferentes subcategorias de empreendedorismo, a exemplo da social, da tecnológica e da internacional (Ratten, 2010). Revisou produções que tratam sobre a responsabilidade social, a filantropia e o empreendedorismo no segmento de esporte, enfatizando as principais limitações de negócios esportivos (Ratten \& Babiak, 2010). Estudou sobre o marketing esportivo internacional e a sua relação com as disciplinas de negócios internacionais, focando em relevantes eventos como as Olimpíadas e a Copa do Mundo (Ratten \& Ratten, 2011). Identificou os motivos pelos quais as organizações patrocinam 
eventos esportivos em nível comunitário, baseada na premissa de que a política esportiva tem sido influenciada por iniciativas de responsabilidade social corporativa (Miragaia, Ferreira, \& Ratten, 2017). Analisou a relação entre o desempenho dos clubes profisssionais de futebol europeu e a estabilidade de sua eficiência financeira (Miragaia, Ferreira, Carvalho, \& Ratten, 2019).

Jacob Hoerisch tratou sobre contribuições acadêmicas e iniciativas que relacionam o empreendedorismo e a sustentabilidade, bem como abordou alternativas de financiamento para empreendimentos sustentáveis. Sintetizou estudos sobre empreendedorismo sustentável, sustentabilidade e Ecopreneurship (Hoerisch, 2015b). Revisou artigos sobre a contribuição de diferentes atores e negócios para as transições vinculadas à sustentabilidade (Hoerisch, 2016). Analisou a relação entre a dimensão ambiental e o sucesso do crowdfunding, que corresponde à prática de financiamento coletivo ou colaborativo (Hoerisch, 2015a). Identificou e categorizou características comuns em projetos de financiamentos coletivos para empreendimentos sustentáveis, bem como analisou os propulsores do sucesso financeiro e de marketing dos projetos de financiamento coletivo (Hoerisch, 2018a).

Comparou empreendedores nascentes com empreendedores estabelecidos no que se refere à orientação ambiental de seus empreendimentos (Hoerisch, Kollat, \& Brieger, 2019). Investigou como diferentes negócios podem reagir às mudanças direcionadas à sustentabilidade (Hoerisch, 2018b). Analisou os efeitos da orientação ambiental em redes de startups (Dickel, Hoerisch, \& Ritter, 2018). Analisou práticas corporativas de grandes empresas internacionais, para capturar como as empresas estão lidando com o gerenciamento da sustentabilidade (Schaltegger \& Hoerisch, 2017). Descreveu conceitos de sustentabilidade no âmbito das empresas multinacionais, destacando sinergias entre os conceitos de sustentabilidade corporativa e de empreendedorismo corporativo (Blazejewski \& Hoerisch, 2017).

Esses resultados confirmam a Lei de Lotka, dado que são poucos os autores mais produtivos na amostra investigada, supostamente com maior prestígio, e muitos os autores com pouca publicação (Egghe, 2005). Vanessa Ratten e Jacob Hoerisch estudam diferentes eixos temáticos associados ao empreendedorismo, a dispersão da produção científica pôde ser observada a partir da amostra considerada neste estudo. Deste modo, verifica-se que o paradigma da sustentabilidade que estabelece uma interseção entre negócio e sociedade é o principal aspecto que interliga os estudos dos autores mais prolíferos, pois ambos estudam diferentes tópicos a respeito do empreendedorismo. 


\subsection{Redes de coocorrência de palavras-chave}

A relação de coocorrência entre duas palavras-chave é determinada pela quantidade de publicações nas quais ambas ocorrem juntas no título, no resumo ou na lista de palavras-chave (Perianes-Rodriguez, Waltman, \& van Eck, 2016). Para analisar a rede de coocorrência de palavras-chave que demonstram uma relação entre si e com os outros termos, formou-se uma rede restrita a palavras-chave com no mínimo 20 ocorrências, o que resultou em 106 palavraschave, distribuídas em cinco clusters, conforme observado na Figura 1.

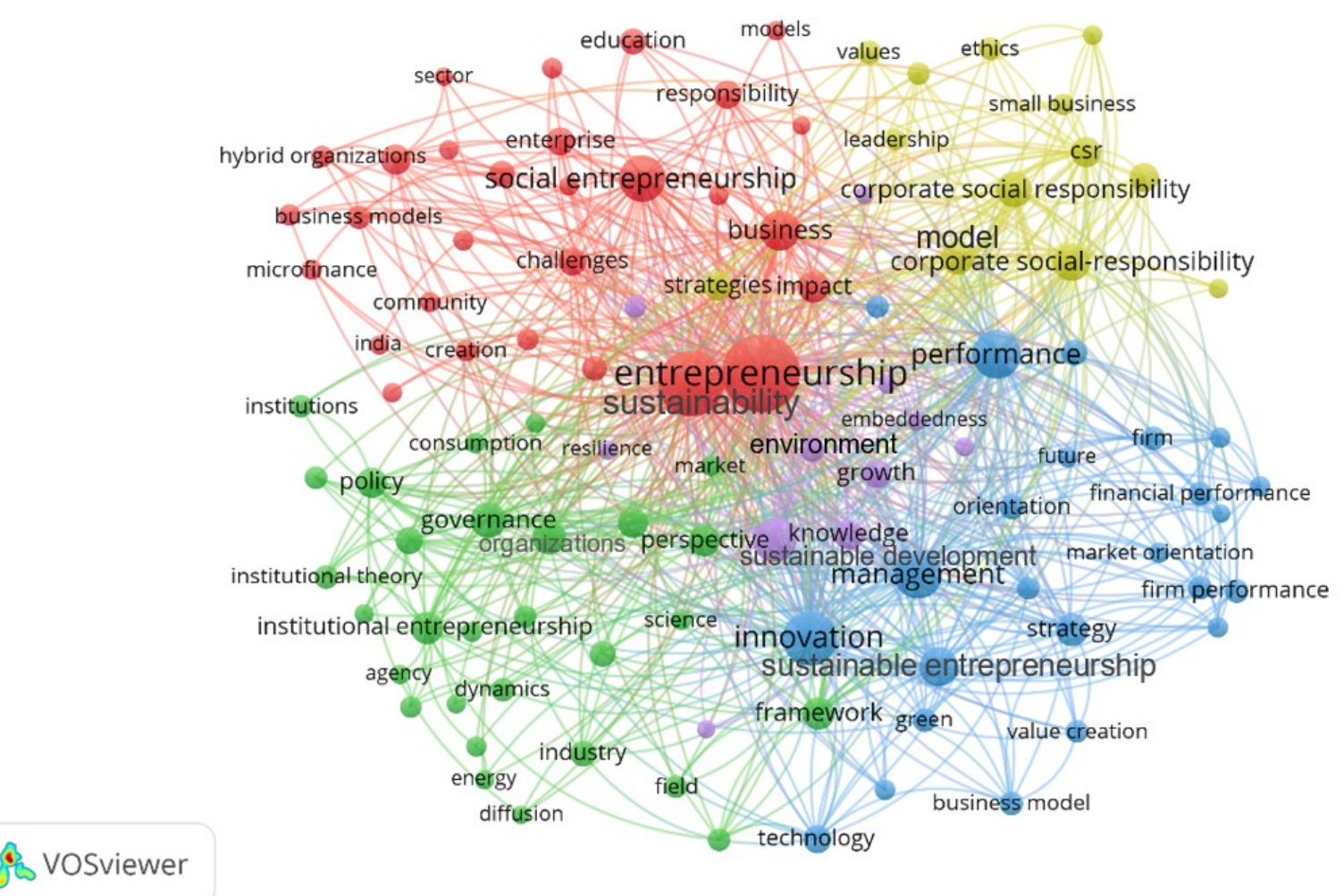

Figura 1. Análise de coocorrência de palavras-chave

Fonte: Dados da pesquisa (2020)

O primeiro cluster (cor vermelha) agrupou 29 palavras-chave, e as que obtiveram mais ocorrência foram: Entrepreneurship, Sustainability, Social Entrepreneurship e Business. Esse conjunto sugere pesquisas que combinam o empreendedorismo convencional com a perspectiva da sustentabilidade, sobretudo com a dimensão social. As pesquisas sobre o empreendedorismo social abordam quatro elementos principais: visão do comportamento humano, justiça social e equidade, lucro como um meio para um fim e colaboração participativa (Schaefer, Corner, \& Kearins, 2015). 
O segundo cluster (cor verde) reuniu 29 palavras-chave, com destaque para: Governance, Organizations, Perspective, Framework e Institutional Entrepreneurship. Essas palavras permitem inferir o desenvolvimento de estudos no campo do empreendedorismo institucional, abordado dentro da perspectiva sociológica da teoria institucional, que chama a atenção para o reflexo de atores organizados e de outros recursos em determinado campo organizacional (Brown et al., 2009).

O terceiro cluster (cor azul escuro) foi constituído por 24 palavras-chave, sendo as mais citadas: Innovation, Performance, Management e Sustainable Entrepreneurship. Esse conjunto sugere pesquisas que abordam as relações entre a inovação e o empreendedorismo, à luz da perspectiva da sustentabilidade. Além dos impactos do mercado, o desenvolvimento sustentável requer um tipo de inovação que muda o ambiente de negócios, as regulamentações de mercado e as instituições da sociedade. Esses processos criam tendências sociais ou inovações regulatórias que possibilitam o florescimento do consumo sustentável, bem como o desenvolvimento de processos e de produtos competitivos e sustentáveis (Schaltegger \& Wagner, 2011)

O quarto cluster (cor amarelo) é constituído por 13 palavras-chave, as mais citadas foram: Corporate social-responsibility, Corporate social responsibility e model. Tais ocorrências permitem inferir que há uma linha de pesquisas abordando modelos de negócio baseados em responsabilidade social. A conexão entre Responsabilidade Social Empresarial e o empreendedorismo tem um significativo potencial para exploração, pois cada vez mais os empreendedores estão usando princípios empresariais para gerar impactos sociais e ambientais positivos (Ratten \& Babiak, 2010).

O quinto cluster (cor lilás) integra 11 palavras-chave, com evidência para: Sustainable development, Knowledge, Environment e Growth. A linha de pesquisa que tais palavras sugere é voltada para casos de empresas que estão incluindo a sustentabilidade em suas operações com ênfase na dimensão ambiental, bem como pode se relacionar com iniciativas de gestão do conhecimento em relação ao tema. As questões ambientais podem exercer influência nos negócios pelas seguintes razões: legislação e controle governamentais, pressões das partes interessadas, motivação ética (responsabilidade social corporativa) e competitividade (resultante da redução de custos ou do aumento de receita através de práticas ambientais) (York, O’Neil, \& Sarasvathy, 2016).

Com base na Lei de Zipf, esta análise também possibilita identificar possíveis linhas de pesquisa sobre o empreendedorismo sustentável, uma vez que apresenta os termos de maior frequência. Deste modo, através da análise de coocorrência de palavras-chave é 
possível identificar cinco linhas de pesquisa: 1) empreendedorismo social, 2) empreendedorismo institucional, 3) inovação e sustentabilidade, 4) responsabilidade social e 5) sustentabilidade ambiental nas organizações.

Observa-se que os clusters 1 e 4 se associam à dimensão social do conceito de desenvolvimento sustentável, enquanto o cluster 5 está relacionado à dimensão ambiental. Por sua vez, os clusters 2 e 3 sugerem pesquisas sobre o empreendedorismo institucional e a inovação, esses construtos convergem ao tratar sobre adaptações e processos de mudanças em diferentes estruturas organizacionais, assim, são conceitos interligados ao empreendedorismo convencional e à sustentabilidade, conforme observado em Vaz e Nijkamp (2009), Brown et al. (2009) e Oukil (2009).

\subsection{Redes de cocitação}

Em uma análise de cocitação, a relação entre os pesquisadores é determinada com base na quantidade com que são citados nas mesmas publicações. Isto é, quanto mais dois pesquisadores são referenciados nas mesmas publicações, maior a sua relação (PerianesRodriguez et al., 2016). A Figura 2 revela a rede de cocitações entre os autores, considerando como parâmetro de corte o número de 40 citações por autor, gerando uma rede de 187 autores distribuídos em seis clusters.

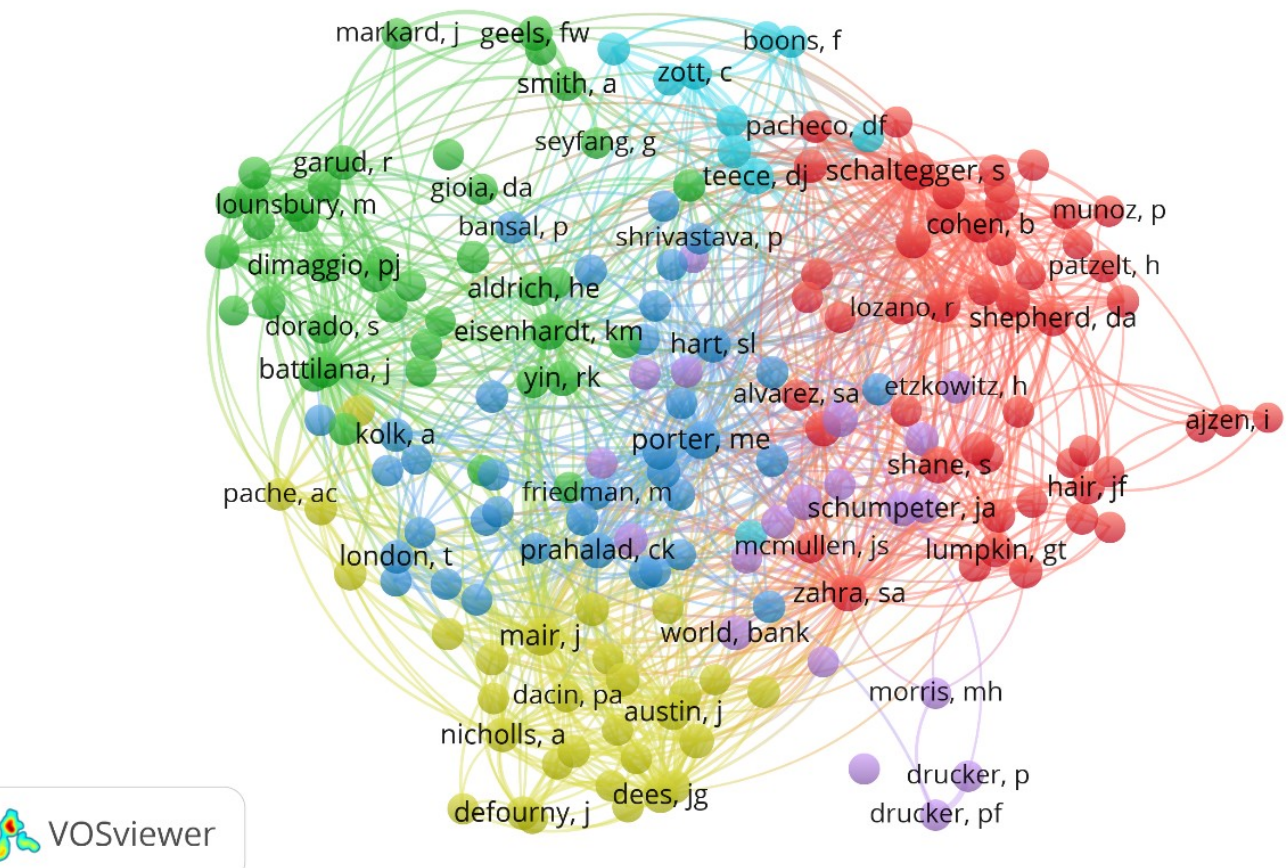

Figura 2. Redes de cocitação

Fonte: Dados da pesquisa (2020) 
O primeiro cluster (cor vermelha) foi formado por 50 autores, sendo os mais relevantes, nesta ordem: Stefan Schaltegger, Shaker A. Zahra e Boyd Cohen. As investigações realizadas por esses pesquisadores tratam sobre o empreendedorismo sustentável, com ênfase nas dimensões social e ambiental. Mais sobre este cluster pode ser consultado nas seguintes publicações: Schaltegger e Wagner (2011), Schaltegger (2002), Zahra, Gedajlovic, Neubaum e Shulman (2009) e Cohen e Winn (2007).

O segundo cluster (cor verde) foi constituído por 40 autores, evidenciando-se como mais citados, nesta ordem: Julie Battilana e Kathleen M. Eisenhardt. Essas autoras vêm desenvolvendo pesquisas sobre os processos de construção e de evolução de teorias, a exemplo da teoria institucional, conforme pode ser verificado nos principais estudos: Battilana, Leca, e Boxenbaum (2009), Battilana e Dorado (2010), bem como Battilana e Lee (2014), Eisenhardt (1989) e Eisenhardt e Graebner (2007).

O terceiro cluster (cor azul escuro) agrupou 37 autores, sendo os mais citados: Michael Eugene Porter, Stuart L. Hart e Coimbatore Krishnarao Prahalad. As investigações realizadas por esses autores estão relacionadas a estratégias de competitividade e ao desempenho das organizações em resposta à sustentabilidade, segundo as seguintes obras: Porter e Kramer (2007), Porter e Kramer (2011), Hart (1995), Hart, Milstein e Caggiano (2003), Prahalad e Hammond (2002) e Prahalad e Hart (2002).

O quarto cluster (cor amarela) é constituído por 30 autores, cujos mais citados foram: Johanna Mair, Gregory Dees e James Austin. Esses autores contribuem para as pesquisas na área ao investigar sobre impactos sociais provocados pelos empreendimentos, conforme o exposto nas seguintes obras: Mair e Martí (2006), Dees (1998) e Austin, Stevenson, e WeiSkillern (2006).

O quinto cluster (cor lilás) é instituído por 20 referências, cujo autor mais citado foi o economista e cientista político Joseph Schumpeter, que elucida características de uma economia moderna, conforme consultado em Schumpeter (1934). Por sua vez, o último cluster (cor azul claro), instituído por 10 autores, centraliza-se em David John Teece, que explorou a relação entre a estratégia de negócios, o gerenciamento da inovação e a teoria econômica, como consultado em Teece (2010).

Por meio das redes de cocitação foi possível identificar as similaridades entre os pesquisadores, uma vez que os artigos analisados foram organizados em seis clusters: 1) empreendedorismo social e ambiental, 2) processos de construção e de evolução de teorias, 3) competitividade e sustentabilidade, 4) negócios de impactos social, 5) desenvolvimento econômico e 6) estratégia, inovação e economia. 
Deste modo, verifica-se que os estudos estão distribuídos em três grupos principais: i) estudos sobre a construção e a evolução de teorias (cluster 2), ii) pesquisas relacionadas às dimensões da sustentabilidade de forma isolada ou de maneira combinada (clusters 1 e 4), iii) produções referentes à economia e à gestão estratégica (clusters 3,5 e 6), este grupo evidencia que o conceito de sustentabilidade não se limita à mitigação ou à resolução de problemas ambientais, mas conecta estratégias socioambientais e estratégias econômicas (Silveira, Backes, \& Kobayashi, 2018).

Como exposto por Small (1973), estes dados apontam as principais referências citadas juntas pela literatura posterior. Assim, o primeiro grupo é formado por Julie Battilana e Kathleen M. Eisenhardt. O segundo grupo é constituído por Schaltegger, Shaker A. Zahra, Boyd Cohen, Johanna Mair, Gregory Dees e James Austin. O terceiro grupo é composto por Michael Eugene Porter, Stuart L. Hart, Coimbatore Krishnarao Prahalad, Joseph Schumpeter e David John Teece.

\subsection{Redes de coautoria}

$\mathrm{Na}$ análise de redes de coautoria, pesquisadores, instituições de pesquisa ou países estão ligados entre si com base no volume de publicações que eles desenvolvem em conjunto (Perianes-Rodriguez et al., 2016). As redes de coautoria foram mapeadas, considerando autores com pelo menos quatro documentos e uma citação. Com esse filtro, foi gerada uma rede com 25 autores dispostos em três clusters. A Figura 3 apresenta as principais redes de coautoria mapeadas, com evidência para sete autores.

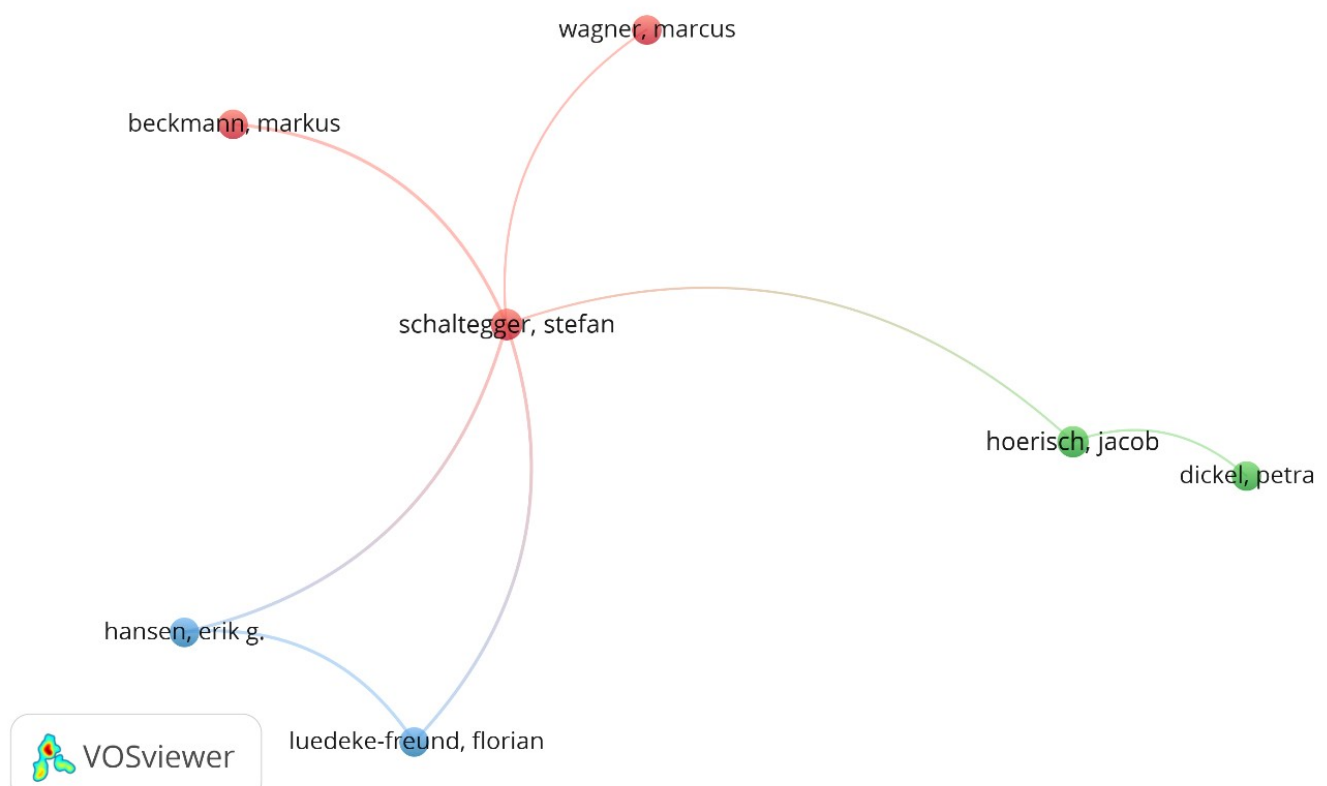


Figura 3. Redes de coautoria

Fonte: Dados da pesquisa (2020)

O primeiro cluster (cor vermelha), formado por três autores, centraliza-se em Stefan Schaltegger e tem como demais participantes: Markus Beckmann e Wagner Marcus. Os autores destacam-se pela exploração de vínculos entre o desenvolvimento sustentável e diferentes formas de empreendedorismo, a exemplo do empreendedorismo social, do empreendedorismo político, do empreendedorismo colaborativo, dentre outros. Esses aspectos podem ser constatados em Schaltegger e Wagner (2011), Schaltegger, Beckmann e Hockerts (2018b), Schaltegger, Beckmann e Hockerts (2018a), entre outros.

O segundo cluster (cor verde) é constituído por Jacob Hoerisch e Petra Dickel, que versam sobre contribuições teóricas e práticas de empreendedorismo em relação à sustentabilidade, conforme observado em Hoerisch (2015a), Hoerisch (2016), Hoerisch (2018a) e Dickel et al. (2018).

O terceiro cluster (cor azul claro) polariza-se em torno de Erik G. Hansen e Florian Luedeke-Freund, que desenvolvem pesquisas sobre os efeitos do empreendedorismo sustentável nos mercados e na sociedade, como observado nas seguintes pesquisas: Klewitz e Hansen (2014), Abdelkafi e Hansen (2018), Luedeke-Freund (2020) e Schaltegger et al., (2016).

Relacionando os dados de coautoria com o exposto por Silva et al. (2017), verifica-se que Jacob Hoerisch e Petra Dickel (cluster 2) e Erik G. Hansen e Florian Luedeke-Freund (cluster 3) contribuem com a produção científica sobre o empreendedorismo sustentável. Já Stefan Schaltegger, Markus Beckmann e Wagner Marcus, que integram o cluster 1, possuem produções em diferentes subcampos do empreendedorismo. Para Landström, Harirchi, e Åström (2012), o campo de conhecimento sobre empreendedorismo cresceu significativamente e tornou-se um tema de interesse entre os pesquisadores de diferentes áreas. Assim, esse campo de estudo ficou mais heterogêneo, com subgrupos de estudos, movimentando-se em vertentes diferentes.

\section{Considerações finais}

Este trabalho teve por objetivo mapear a produção científica internacional sobre empreendedorismo sustentável, a partir de uma exploração de artigos publicados na base Web Of Science, entre 2009 e 2019. Foram delineados a evolução da produção científica sobre o 
tema, os autores mais prolíficos e as fontes de publicação com maior volume de produções, bem como analisadas as redes bibliométricas de coocorrência de palavras-chave, de coautoria e de cocitação.

A quantidade de publicações sobre o tema está em ascensão desde 2014, e o alto número de publicações é encontrado para o período entre 2015 e 2019, sendo 2019 o ano com maior concentração da produção científica. Os 1.430 documentos que constituem a base de dados estão distribuídos em 562 fontes de publicação, o que evidencia a dispersão da pesquisa no campo. Os journals que concentram a maior quantidade de publicações são o Sustainability e o Journal of Cleaner Production. Os autores com a quantidade de publicações mais expressiva são Vanessa Ratten e Jacob Hoerisch. Vanessa Ratten destaca-se ao conectar as literaturas de empreendedorismo, gestão esportiva e responsabilidade social. Já Jacob Hoerisch trata sobre contribuições acadêmicas e iniciativas que relacionam o empreendedorismo e a sustentabilidade, bem como estuda sobre financiamentos coletivos.

Por meio de algoritmos de clusters, efetuou-se o mapeamento de redes de coocorrência de palavras-chave, de cocitação e de coautoria. A análise de coocorrência de palavras-chave permitiu mapear cinco linhas de pesquisa: a primeira linha sugere pesquisas sobre o empreendedorismo social. A segunda linha indica estudos no campo do empreendedorismo institucional. A terceira linha aponta o desenvolvimento de pesquisas sobre inovação e sustentabilidade. A quarta linha compreende investigações sobre responsabilidade social. Por sua vez, a quinta linha sugere pesquisas sobre a sustentabilidade ambiental nas organizações.

Através das redes de cocitação foi possível identificar as similaridades entre os pesquisadores, uma vez que os artigos analisados foram organizados em seis clusters: o primeiro cluster envolve pesquisas sobre empreendedorismo com ênfase nas dimensões social e ambiental. O segundo cluster vem desenvolvendo pesquisas sobre processos de construção e de evolução de teorias. O terceiro cluster agrupou pesquisas que relacionam estratégias de competitividade e sustentabilidade. O quarto cluster reúne estudos sobre negócios de impacto social. O quinto cluster trata de aspectos relativos ao desenvolvimento econômico. O sexto cluster relaciona abordagens de estratégia, inovação e economia.

Quanto às redes de coautoria, verificou-se a existência de três clusters de colaboração de pesquisa, evidenciando a concentração de estudos no campo do empreendedorismo sustentável e do empreendedorismo convencional, com destaque para os seguintes autores: Stefan Schaltegger, Markus Beckmann, Wagner Marcus, Jacob Hoerisch, Petra Dickel, Erik G. Hansen e Florian Luedeke-Freund. 
Conclui-se que o tema está em evolução no cenário internacional, e os dados possibilitaram verificar uma grande dispersão nos estudos sobre este campo do conhecimento. Não foram identificados grandes clusters de estudos, no entanto observaram-se investigações relacionadas à estrutura conceitual do empreendedorismo tradicional, integrando as dimensões social e ambiental da sustentabilidade à inovação, à gestão estratégica e ao empreendedorismo institucional.

Esta pesquisa contribuiu para a ampliação do conhecimento na área, pois vislumbra de maneira geral quais as temáticas encontradas na literatura internacional sobre $o$ empreendedorismo sustentável, proporcionando um respaldo teórico para vários estudos futuros mais direcionados e objetivos. Destacam-se como principais limitações do estudo: a utilização da base de dados Web of Science como única fonte de coleta de dados, bem como o fato de não serem selecionados apenas periódicos específicos da área de Gestão e Negócios.

Sugere-se para estudos posteriores a utilização de outras metodologias e de diferentes bases de dados, objetivando a construção de um portfólio bibliográfico de modo que as linhas de pesquisa sobre o empreendedorismo sustentável sejam exploradas minuciosamente, além da realização de estudos que apresentam a contribuição de autores brasileiros sobre o tema.

\section{Referências}

Abdelkafi, N., \& Hansen, E. G. (2018). Ecopreneurs' creation of user business models for green tech: an exploratory study in e-mobility. International Journal Of Entrepreneurial Venturing, 10(1), 32-55. https://doi.org/10.1504/IJEV.2018.10007848

Austin, J., Stevenson, H., \& Wei-Skillern, J. (2006). Social and Commercial Entrepreneurship: Same, Different, or Both?. Entrepreneurship theory and practice, 30(1), 1-22. https://doi.org/10.1111/j.1540-6520.2006.00107.x

Bansal, S., Garg, I., \& Sharma, G. D. (2019). Social entrepreneurship as a path for social change and driver of sustainable development: A systematic review and research agenda. Sustainability (Switzerland), 11(4). https://doi.org/10.3390/su11041091

Battilana, J., \& Dorado, S. (2010). Building Sustainable Hybrid Organizations: The Case Of Commercial Microfinance Organizations. Academy of Management Journal, 53(6), 1419-1440. https://doi.org/10.5465/AMJ.2010.57318391

Battilana, J., Leca, B., \& Boxenbaum, E. (2009). 2 How Actors Change Institutions: Towards a Theory of Institutional Entrepreneurship. The Academy of Management Annals, 3(1), 65-107. https://doi.org/10.1080/19416520903053598 
Battilana, J., \& Lee, M. (2014). Advancing Research on Hybrid Organizing - Insights from the Study of Social Enterprises. Academy of Management Annals, 8(1), 397-441. https://doi.org/10.1080/19416520.2014.893615

Blazejewski, S., \& Hoerisch, J. (2017). Editorial: Challenges and opportunities for multinational corporations in sustainable development. International Journal of Business Environment, 9(3), 201-209. https://doi.org/10.1504/IJBE.2017.087992

Borges, C., Borges, M. M., Ferreira, V. Da R. S., Najberg, E., \& Tete, M. F. (2014). Empreendedorismo Sustentável. São Paulo: Saraiva.

Boszczowski, A. K., \& Teixeira, R. M. (2012). O empreendedorismo sustentável e o processo empreendedor: em busca de oportunidades de novos negócios como solução para problemas sociais e ambientais. Revista Economia e Gestão, 12(29), 141-168. https://doi.org/10.5752/P.1984-6606.2012v12n29p109

Brown, H. S., de Jong, M., \& Lessidrenska, T. (2009). The rise of the Global Reporting Initiative: a case of institutional entrepreneurship. Environmental Politics, 18(2), 182200. https://doi.org/10.1080/09644010802682551

Cicconi, E. G. (2013). Empreendedorismo. In Porto, G. S. Gestão da inovação e empreendedorismo, p. 1-14, Rio de Janeiro: Elsevier.

Cohen, B., \& Winn, M. I. (2007). Market imperfections, opportunity and sustainable entrepreneurship. Journal of Business Venturing, 22(1), 29-49. https://doi.org/10.1016/j.jbusvent.2004.12.001

Dees, J. G. (1998). Enterprising nonprofits: What do you do when traditional sources of funding fall short. Harvard business review, 76, 55-67.

Dickel, P., Hoerisch, J., \& Ritter, T. (2018). Networking for the environment: The impact of environmental orientation on start-ups' networking frequency and network size. Journal Of Cleaner Production, 179, 308-316. https://doi.org/10.1016/j.jclepro.2018.01.058

Egghe, L. (2005). Zipfian and lotkaian continuous concentration theory. Journal of the American Society for Information Science and Technology, 56(9), 935-945. https://doi.org/10.1002/asi.20186

Eisenhardt, K. M. (1989). Building Theories from Case Study Research. Academy of Management Review, 14(4), 532-550. https://doi.org/10.5465/amr.1989.4308385

Eisenhardt, K. M., \& Graebner, M. E. (2007). Theory building from cases: Opportunities and challenges. Academy of Management Journal, 50(1), 25-32. https://doi.org/10.5465/AMJ.2007.24160888

Gast, J., Gundolf, K., \& Cesinger, B. (2017). Doing business in a green way: A systematic Revista Gestão e Secretariado (GeSec), São Paulo, SP, 12(1), jan./abr., 2021, p. 133-159. 
review of the ecological sustainability entrepreneurship literature and future research directions. Journal of Cleaner Production, 147, 44-56. https://doi.org/10.1016/j.jclepro.2017.01.065

Gibbs, D. M. I. (2009). Sustainability Entrepreneurs, Ecopreneurs and the Development of a Sustainable Economy. Greener Management International, 55, 63-78. https://doi.org/10.9774/gleaf.3062.2006.au.00007

Hall, J. K., Daneke, G. A., \& Lenox, M. J. (2010). Sustainable development and entrepreneurship: Past contributions and future directions. Journal of Business Venturing, 25(5), 439-448. https://doi.org/10.1016/j.jbusvent.2010.01.002

Hart, S. L. (1995). A Natural-Resource-Based View Of The Firm. The Academy of Management Review, 20(4), 986-1014. https://doi.org/10.2307/258963

Hart, S. L., Milstein, M. B., \& Caggiano, J. (2003). Creating sustainable value. Academy of Management Executive, 17(2), 56-69. https://doi.org/10.5465/ame.2003.10025194

Hoerisch, J. (2015a). Crowdfunding for environmental ventures: an empirical analysis of the influence of environmental orientation on the success of crowdfunding initiatives. Journal Of Cleaner Production, 107, 636-645. https://doi.org/10.1016/j.jclepro.2015.05.046

Hoerisch, J. (2015b). The Role of Sustainable Entrepreneurship in Sustainability Transitions: A Conceptual Synthesis against the Background of the Multi-Level Perspective. Administrative Sciences, 5(4), 286-300. https://doi.org/10.3390/admsci5040286

Hoerisch, J. (2016). Entrepreneurship as Facilitator for Sustainable Development? Editorial for the Special Issue "Advances in Sustainable Entrepreneurship". Administrative Sciences, 6(1). https://doi.org/10.3390/admsci6010004

Hoerisch, J. (2018a). 'Think big' or 'small is beautiful'? An empirical analysis of characteristics and determinants of success of sustainable crowdfunding projects. International Journal Of Entrepreneurial Venturing, 10(1), 111-129. https://doi.org/10.1504/IJEV.2018.090982

Hoerisch, J. (2018b). How business actors can contribute to sustainability transitions: A case study on the ongoing animal welfare transition in the German egg industry. Journal of Cleaner Production, 201, 1155-1165. https://doi.org/10.1016/j.jclepro.2018.08.031

Hoerisch, J., Kollat, J., \& Brieger, S. A. (2019). Environmental orientation among nascent and established entrepreneurs: an empirical analysis of differences and their causes. International Journal Of Entrepreneurial Venturing, 11(4), 373-393. https://doi.org/10.1504/IJEV.2019.101623 
Journal of Cleaner Production. (2020). Aims and scope. Recuperado de https://www.elsevier.com/journals/journal-of-cleaner-production/0959-6526/guide-forauthors

Klewitz, J., \& Hansen, E. G. (2014). Sustainability-oriented innovation of SMEs: A systematic review. Journal of Cleaner Production, 65, 57-75. https://doi.org/10.1016/j.jclepro.2013.07.017

Knutas, A., Hajikhani, A., Salminen, J., Ikonen, J., \& Porras, J. (2015). Cloud-based bibliometric analysis service for systematic mapping studies. Proceedings of the 16th International Conference on Computer Systems and Technologies, 184-191. https://doi.org/10.1145/2812428.2812442

Landström, H., Harirchi, G., \& Åström, F. (2012). Entrepreneurship: Exploring the knowledge base. Research Policy, 41(7), 1154-1181. https://doi.org/10.1016/j.respol.2012.03.009

Luedeke-Freund, F. (2020). Sustainable entrepreneurship, innovation, and business models: Integrative framework and propositions for future research. Business Strategy And The Environment, 29(2), 665-681. https://doi.org/10.1002/bse.2396

Mair, J., \& Martí, I. (2006). Social entrepreneurship research: A source of explanation, prediction, and delight. Journal of World Business, 41(1), 36-44. https://doi.org/10.1016/j.jwb.2005.09.002

Majid, I. A., \& Koe, W. L. (2012). Sustainable Entrepreneurship: a revised model based on triple bottom line (TBL). International Journal of Academic Research in Business and Social Sciences, 2(6), 293-310.

Miragaia, D. A. M., Ferreira, J., \& Ratten, V. (2017). Corporate social responsibility and social entrepreneurship: drivers of sports sponsorship policy. International Journal of Sport Policy And Politics, 6(4), 613-623. https://doi.org/10.1080/19406940.2017.1374297

Miragaia, D., Ferreira, J., Carvalho, A., \& Ratten, V. (2019). Interactions between financial efficiency and sports performance Data for a sustainable entrepreneurial approach of European professional football clubs. Journal Of Entrepreneurship And Public Policy, 8(1), 84-102. https://doi.org/10.1108/JEPP-D-18-00060

Oliveira, S. C. M, \& et al. (2013). Bibliometria em artigos de contabilidade aplicada ao setor público. Artigo apresentado no Congresso Brasileiro de Custos, Associação Brasileira de Custos, São Leopoldo, Brasil.

Oukil, M. S. (2009). Enhancing innovation for sustainable growth and competitiveness in Revista Gestão e Secretariado (GeSec), São Paulo, SP, 12(1), jan./abr., 2021, p. 133-159. 
North African countries. International Journal Of Technology Management, 45(1-2), 114-122. https://doi.org/10.1504/IJTM.2009.021523

Parrish, B. (2010). "Sustainability-driven entrepreneurship: Principles of organization design". Journal of Business Venturing, 25(5), 510-523. https://doi.org/10.1016/j.jbusvent.2009.05.005

Parrish, B. D., \& Foxon, T. J. (2009). Sustainability Entrepreneurship and Equitable Transitions to a Low-Carbon Economy. Green Management International, 55(1), 47-62. https://doi.org/10.9774/GLEAF.3062.2006.au.00006

Perianes-Rodriguez, A., Waltman, L., \& van Eck, N. J. (2016). Constructing bibliometric networks: A comparison between full and fractional counting. Journal of Informetrics, 10(4), 1178-1195. https://doi.org/10.1016/j.joi.2016.10.006

Porter, M. E., \& Kramer, M. R. (2007). Strategy and society: The link between competitive advantage and corporate social responsibility-response. Harvard Business Review, 85 (12), 139-139.

Kramer, M. R., \& Porter, M. (2011). Creating shared value. FSG.

Prahalad, C. K., \& Hammond, A. (2002). Serving the world's poor, profitably. Harvard Business Review, 80(9), 48-57.

Prahalad, C. K., \& Hart, S. L. (2002). The Fortune at the Bottom of the Pyramid. Estratégia e negócios, 26, 54-67. https://doi.org/10.19177/reen.v1e220081-23

Ratten, V. (2010). Developing a theory of sport-based entrepreneurship. Journal Of Management \& Organization, 16(4), 557-565. https://doi.org/10.5172/jmo.2010.16.4.557

Ratten, V., \& Babiak, K. (2010). The role of social responsibility, philanthropy and entrepreneurship in the sport industry. Journal Of Management \& Organization, 16(4), 482-487. https://doi.org/10.1017/S1833367200001875

Ratten, V., \& Ratten, H. (2011). International sport marketing: practical and future research implications. Journal Of Business \& Industrial Marketing, 26(8), 614-620. https://doi.org/10.1108/08858621111179886

Richomme-Huet, K., \& Freyman, J. D. (2011). What Sustainable Entrepreneurship Looks Like: An Exploratory Study from a Student Perspective. Artigo apresentado na Conference proceedings in 56th Annual International Council for Small Business (ICSB), World Conference. Stockholm, Sweden.

Schaefer, K., Corner, P. D., \& Kearins, K. (2015). Social, Environmental and Sustainable Entrepreneurship Research: What Is Needed for Sustainability-as-Flourishing? Revista Gestão e Secretariado (GeSec), São Paulo, SP, 12(1), jan./abr., 2021, p. 133-159. 
Organization and Environment, 28(4), 394-413. https://doi.org/10.1177/1086026615621111

Schaltegger, S. (2002). A Framework for Ecopreneurship. Greener Management International, 38 (38), 45-58. https://doi.org/10.9774/gleaf.3062.2002.su.00006

Schaltegger, S., Beckmann, M., \& Hockerts, K. (2018a). Collaborative entrepreneurship for sustainability. Creating solutions in light of the UN sustainable development goals. International Journal Of Entrepreneurial Venturing, 10(2), 131-152. https://doi.org/10.1504/IJEV.2018.092709

Schaltegger, S., Beckmann, M., \& Hockerts, K. (2018b). Sustainable entrepreneurship: creating environmental solutions in light of planetary boundaries. International Journal Of Entrepreneurial Venturing, 10(1), 1-16. https://doi.org/10.1504/IJEV.2018.090990

Schaltegger, S., \& Hoerisch, J. (2017). In Search of the Dominant Rationale in Sustainability Management: Legitimacy- or Profit-Seeking? Journal Of Business Ethics, 145(2), 259276. https://doi.org/10.1007/s10551-015-2854-3

Schaltegger, S., Luedeke-Freund, F., \& Hansen, E. G. (2016). Business Models for Sustainability: A Co-Evolutionary Analysis of Sustainable Entrepreneurship, Innovation, and Transformation. Organization \& Environment, 29(3), 264-289. https://doi.org/10.1177/1086026616633272

Schaltegger, S., \& Wagner, M. (2011). Sustainable Entrepreneurship and Sustainability Innovation: Categories and Interactions. Business Strategy And The Environment, 20(4), 222-237. https://doi.org/10.1002/bse.682

Schumpeter, J. A. (1934). A teoria do desenvolvimento econômico: uma investigação sobre lucros, capital, crédito, juros e ciclo de negócios. Massachusetts: Cambridge.

Shepherd, D. A., \& Patzelt, H. (2011). The New Field of Sustainable Entrepreneurship: Studying Entrepreneurial Action Linking "What Is to Be Sustained" With "What Is to Be Developed". Entrepreneurship: Theory and Practice, 35(1), 137-163. https://doi.org/10.1111/j.1540-6520.2010.00426.x

Silva, A. C. C., Durante, D. G., \& Biscoli, F. R. V. (2017). Espiritualidade no ambiente de trabalho: estudo bibliométrico da produção acadêmica nacional. Revista de Gestão e Secretariado, 8(2), 1-19. https://doi.org/10.7769/gesec.v8i2.594

Silveira, A., Backes, D. A. P., \& Kobayashi, A. R. K. (2018). Sustainable entrepreneurship: the scientific production of the 21st century. Revista de Negócios, 22(3), 01-16. https://doi.org/10.7867/1980-4431.2017v22n3p22-37

Small, H. (1973). Co-citation in the scientific literature: a new measure of the relationship Revista Gestão e Secretariado (GeSec), São Paulo, SP, 12(1), jan./abr., 2021, p. 133-159. 
between two documents. Journal of the American Society for Information Science and Technology, 24(4), 265-269. https://doi.org/10.1002/asi.4630240406

Sustainability. (2020). About Sustainability. Recuperado de https://www.mdpi.com/journal/sustainability/about

Tarnanidis, T., Papathanasiou, J., \& Subeniotis, D. (2019). How Far the TBL Concept of Sustainable Entrepreneurship Extends Beyond the Various Sustainability Regulations: Can Greek Food Manufacturing Enterprises Sustain Their Hybrid Nature Over Time? Journal of Business Ethics, 154(3), 829-846. https://doi.org/10.1007/s10551-017-3443-4

Teece, D. J. (2010). Business models, business strategy and innovation. Long Range Planning, 43(2-3), 172-194. https://doi.org/10.1016/j.lrp.2009.07.003

Thananusak, T. (2019). Science mapping of the knowledge base on sustainable entrepreneurship, 1996-2019. Sustainability (Switzerland), 11(13), 35-65. https://doi.org/10.3390/su11133565

Tilley, F., \& Young, W. (2009). Sustainability Entrepreneurs-Could they be the True Wealth Generators of the Future? Greener Management International, 55(55), 79-92. https://doi.org/10.9774/GLEAF.3062.2006.au.00008

Vallaster, C., Kraus, S., Kailer, N., \& Baldwin, B. (2019). Responsible entrepreneurship: outlining the contingencies. International Journal of Entrepreneurial Behaviour and Research, 25(3), 538-553. https://doi.org/10.1108/IJEBR-04-2018-0206

Vaz, T. de N., \& Nijkamp, P. (2009). Knowledge and innovation: The strings between global and local dimensions of sustainable growth. Entrepreneurship And Regional Development, 21(4), 441-455. https://doi.org/10.1080/08985620903020094

Veiga, J. E. (2010). Indicadores de sustentabilidade. Estudos Avançados, 24(68), 39-52. https://doi.org/10.1590/S1415-65552005000400014

Whittaker, J. (1989). Creativity and conformity in science: titles, keywords: and co-word analysis. Social Studies of Science, 19(3), 473-496. https://doi.org/10.1177/030631289019003004

York, J. G., O’Neil, I., \& Sarasvathy, S. D. (2016). Exploring Environmental Entrepreneurship: Identity Coupling, Venture Goals, and Stakeholder Incentives. Journal of Management Studies, 53(5), 695-737. https://doi.org/10.1111/joms.12198

Zahra, S. A., Gedajlovic, E., Neubaum, D. O., \& Shulman, J. M. (2009). A typology of social entrepreneurs: Motives, search processes and ethical challenges. Journal of Business Venturing, 24(5), 519-532. https://doi.org/10.1016/j.jbusvent.2008.04.007 
Submetido em: 07.09.2020

Aceito em: $\quad 30.11 .2020$ 